Cahiers $d u$ MONDE RUSSE

\section{Cahiers du monde russe}

Russie - Empire russe - Union soviétique et États indépendants

50/2-3 | 2009

L'Europe orientale, 1650-1730. Crises, conflits et renouveau

\title{
Voluntary Associations in Tsarist RussiaJoseph BRADLEY
}

, Harvard : Harvard University Press, 2009, 366 p.

\section{Alexandre Sumpf}

\section{(2) OpenEdition}

\section{Journals}

Édition électronique

URL : https://journals.openedition.org/monderusse/9750

DOI : 10.4000/monderusse. 9750

ISSN : $1777-5388$

\section{Éditeur}

Éditions de l'EHESS

Édition imprimée

Date de publication : 15 septembre 2009

ISBN : 978-2-7132-2260-3

ISSN : $1252-6576$

\section{Référence électronique}

Alexandre Sumpf, "Voluntary Associations in Tsarist RussiaJoseph BRADLEY », Cahiers du monde russe [En ligne], 50/2-3 | 2009, mis en ligne le 14 janvier 2013, consulté le 03 septembre 2022. URL http://journals.openedition.org/monderusse/9750; DOI : https://doi.org/10.4000/monderusse.9750

Ce document a été généré automatiquement le 3 septembre 2022

Tous droits réservés 


\section{Voluntary Associations in Tsarist RussiaJoseph BRADLEY}

, Harvard : Harvard University Press, 2009, 366 p.

Alexandre Sumpf

\section{Joseph BRADLEY, Voluntary Associations in Tsarist Russia, Science, Patriotism and Civil Society, Harvard : Harvard University Press, 2009, 366 p.}

1 En 1991, dans un chapitre de l'ouvrage charnière Between Tsar and People: Educated Society and the Quest for Public Identity in Late Imperial Russia, Joseph Bradley posait les bases de sa réflexion sur les associations - réflexion qui arrive à maturité avec cet ouvrage, modestement présenté par l'auteur comme une contribution partielle à l'histoire non écrite des associations. En effet, l'historiographie (soviétique et russe, pour l'essentiel) a imposé l'image d'une Russie quasi dépourvue de société civile, sans moteurs ni piliers équivalents à ceux des nations occidentales. Or quiconque, comme Bradley, s'est plongé dans la presse d'avant 1917 ou a consulté les abondants rapports de la police et de l'Ohrana, sait qu'il en allait tout autrement. L'empire foisonnait d'associations locales, voire nationales, dont les congrès se multipliaient comme champignons après la pluie, le réseau de publications spécialisées n'ayant (presque) rien à envier à ses homologues français ou britanniques.

2 Le modèle est nettement tracé en introduction: les associations accueillent des membres volontaires, non désignés, cooptés sans intervention extérieure; elles établissent des statuts écrits, se réunissent régulièrement, possèdent biens immobiliers et mobiliers, poursuivent des objectifs, définis au départ. En d'autres termes, on y trouve des ferments d'une professionnalisation inconcevable sans autonomie, éthique, solidarité et débat. Par ailleurs, les associations coordonnent l'effort commun de scientifiques, de responsables politiques ou administratifs et d'amateurs locaux, tant pour faire progresser la science (par essence internationale) que pour valoriser ressources et découvertes russes. Elles ont 
également vocation pédagogique, «vont au peuple » et finissent même par laisser le peuple venir à elles.

3 Le propos progresse en six étapes. Au premier chapitre, l'expérience russe est replacée dans le champ européen auquel elle appartient indéniablement. Comme bien des chercheurs de sa génération, Bradley effectue le détour par Habermas, dont le concept de "sphère publique » fonctionne plutôt bien ici, même si les travaux convoqués de Joel Mokyr $^{4}$ sur la « révolution du savoir » semblent plus féconds. Chaque chapitre, et parfois certaines sous-parties, établissant un parallèle avec l'expérience française, britannique voire allemande, ces pages intéressantes, mais trop générales, ont l'inconvénient de retarder l'entrée dans le vif du sujet. Les quatre sections suivantes examinent tour à tour cinq associations - autant de bornes sur le parcours vers un embryon de société civile russe, et le dernier chapitre aborde les congrès.

4 La Société libre d'économie (VEO, 1765), ainsi que la Société moscovite d'agriculture (MOSH, 1818) marquent une étape fondamentale dans la conquête (alors réservée à une élite) de la liberté d'expression et de réunion, et sont les premières à se préoccuper de l'éducation des paysans. La Société géographique russe (RGO, 1845) met en valeur l'héritage national par le biais de publications inédites en langue russe. Elle inscrit comme principe l'élection des membres, processus fondamental pour la formation de la société civile dans une nation privée de démocratie ; elle fait aussi largement appel aux correspondants locaux, tirant le bilan de leur expertise plutôt que de la diriger depuis le centre; enfin, elle se préoccupe du bien-être matériel des Russes au travers de son Comité d'économie politique. La Société des amis de l'histoire naturelle (OLEAE, 1865) déploie une pédagogie populaire au travers de musées (Musée polytechnique de Moscou) ou d'expositions temporaires, parfois ambulantes - comme celle de Moscou en 1872. Enfin, la Société technique russe (RTO, $\left.1866^{5}\right)$ développe de façon inédite les écoles pour adultes et les congrès entre pairs, déplaçant ainsi l'éducation de la sphère du contrôle étatique à celle du consensus social pour un dialogue de la société avec elle-même sans truchement officiel. Ce faisant, en ce dernier tiers du xix siècle, les associations légitiment les craintes initiales des autorités qui se sont toujours efforcées, sans vraiment y parvenir, de limiter le nombre des adhésions et de contrôler paroles et actions.

Bradley précise bien qu'il n'entend produire ni une histoire des sciences abordées ici, ni même une histoire institutionnelle précise. Son objectif est de comprendre les interactions, d'une part entre (quelques) membres moteurs, d'autre part entre ces associations et l'État tsariste, voire même avec le reste de la société. À la fois encouragée et crainte par le pouvoir qui voit lui échapper la légitimité et le monopole de la décision, l'activité des associations renforce l'État tout en le contestant. La plupart d'entre elles participent à la constitution d'une fierté civique et patriotique et contribuent à l'amélioration de l'exploitation des ressources nationales. Les cinq associations étudiées ont joué un rôle dans l'émergence d'une sphère intermédiaire fondée sur le savoir, la compétence, la collecte planifiée d'information, le débat ouvert et la volonté d'orienter les politiques publiques, dans une vision partagée du bien commun de la société. Leur évolution s'articule autour de trois moments qui, au cours du siècle, cristallisent la conscience nationale, favorisent leur essor et accroissent leur implication dans la destinée du pays. La victoire sur Napoléon en 1812 réveille le sentiment patriotique ; la défaite de Crimée (1856) et la Grande Réforme (1861) suscitent une période de transparence qui concrétise la tension entre incurie bureaucratique et efficacité 
technocratique; enfin, suite à la terrible famine de 1891-1892, elles obtiennent le droit d'intervenir directement sur le terrain en se substituant à un État incapable de réagir dans l'urgence et de reconsidérer l'organisation socioéconomique afin d'éviter que de telles catastrophes se reproduisent.

6 Le dernier chapitre, qui porte sur les congrès, est de loin le plus convaincant. Il est précédé de pierres d'attente : ainsi les développements consacrés aux questionnaires et aux expositions pèchent par l'absence d'analyse sur les modes de mise en forme, collecte et compilation des résultats, tout aussi formateurs collectivement que les débats à l'occasion des congrès. L'acceptation de règles de travail en commun, l'amplitude des débats " de société », une certaine théâtralité ou ritualité, génèrent un discours entrant inévitablement en opposition avec une politique officielle critiquée pour son insuffisance. Les résolutions votées exigent souvent plus de contrôle, plus de compétence, mais aussi plus d'autonomie pour les structures intermédiaires, comme les associations ou les zemstva. Le bien public qui se négocie ainsi forge des citoyens.

7 On ne saurait reprocher à l'auteur ce dont il s'excuse avec lucidité et modestie dans son préambule. Étant donné le nombre (élevé, contrairement à ce que prétend la doxa) des associations russes, le caractère non représentatif de celles qu'il a choisi d'étudier reste relatif. En revanche, le lecteur ressent une certaine frustration due au non-respect d'une partie du contrat proposé : l'étude des relations internes. Certes, on lit quelques pages sur telle ou telle figure proéminente de chaque association, sur les débats qui les agitent (succinctement), mais rien sur leur vie, sur la pratique de « civilisation » de la société. De même, l'ouvrage, déjà volumineux, ne pouvait traiter du cas des minorités nationales, mais on se prive là d'une réflexion sur la question cruciale concernant l'Empire. Surtout, toute dimension territoriale est ignorée : outre le fait que nombre de ces associations ont pourtant vu le jour à Moscou et non à Saint-Pétersbourg, analyser les rapports entre correspondants locaux plus ou moins amateurs et figures nationales aurait permis de connaître les modes de leurs échanges, les facteurs d'engagement et d'adhésion comme les critères de confiance mutuelle.

Quitte à se limiter à une ou deux associations (ce qui éviterait aussi une certaine redondance), il serait sans doute possible de décrire les conditions, le fonctionnement, les limites de ces échanges; d'en évaluer les résultats pour la promotion professionnelle et sociale, l'harmonisation des critères et la diffusion des pratiques ou des connaissances (notamment par les revues, traitées seulement en marge). Le principal défaut de l'ouvrage réside dans l'écrasante convocation d'un modèle occidental qui empêche la comparaison en arasant les aspérités russes, invalidant au final la thèse initiale en se privant de la démontrer. Conséquence inévitable: les quelques lignes évoquant 1917 (sans distinguer entre les deux révolutions...) trahissent la dimension sociale de l'événement, d'autant que l'on ne peut plus vraiment traiter aujourd'hui de la période tsariste sans la mettre à l'épreuve de la Grande Guerre. Espérons que les futures recherches de l'auteur, qui a le mérite indéniable d'avoir mis en lumière ces associations sans toutefois en restituer la vitalité, le mèneront sur ces pistes tout aussi peu fréquentées. 


\section{NOTES}

4. Joel Mokyr, The Gifts of Athena: Historical Origins of the Knowledge Economy, Princeton: Princeton University Press, 2002.

5. Respectivement: VEO: Vol'noe ekonomičeskoe obščestvo; MOSH : Moskovskoe obščestvo sel'skogo hozjajstva; RGO: Russkoe geografičeskoe obščestvo; OLEAE: Obščestvo ljubitelej estestvoznanija, antropologii i etnografii; RTO: Russkoe tehničeskoe obščestvo. 